Biol. Proced. Online 2003;5(1): 204-210.

\title{
A screen to identify drug resistant variants to target-directed anti- cancer agents
}

\author{
Mohammad Azam', Tal Raz, Valentina Nardi, Sarah L. Opitz and George Q. Daley*
}

'Azam and Raz contributed equally to this manuscript.

Department of Biological Chemistry and Molecular Pharmacology, Harvard Medical School and Division of Pediatric Hematology/Oncology, Children's Hospital and Dana Farber Cancer Institute, Boston, MA 02115 USA.

*To whom correspondence should be addressed: George Q. Daley, Children's Hospital, 300 Longwood Ave, Boston, MA 02115 USA. Phone: (617) 258-7209; Fax: (617) 258-5213; Email: george.daley@childrens.harvard.edu

Submitted: August 18, 2003; Revised: October 8, 2003; Accepted: September 24, 2003; Published: October 24,2003

Indexing terms: Genes, ABL; Chronic myeloid leukemia; Drug resistance.

\begin{abstract}
The discovery of oncogenes and signal transduction pathways important for mitogenesis has triggered the development of targetspecific small molecule anti-cancer compounds. As exemplified by imatinib (Gleevec), a specific inhibitor of the Chronic Myeloid Leukemia (CML)-associated Bcr-Abl kinase, these agents promise impressive activity in clinical trials, with low levels of clinical toxicity. However, such therapy is susceptible to the emergence of drug resistance due to amino acid substitutions in the target protein. Defining the spectrum of such mutations is important for patient monitoring and the design of next-generation inhibitors. Using imatinib and $\mathrm{BCR} / \mathrm{ABL}$ as a paradigm for a drug-target pair, we recently reported a retroviral vector-based screening strategy to identify the spectrum of resistance-conferring mutations. Here we provide a detailed methodology for the screen, which can be generally applied to any drug-target pair.
\end{abstract}

\section{INTRODUCTION}

Novel discoveries in cancer biology have provided the opportunity to design target-specific anti-cancer agents and fostered rapid advancements in drug development. The current focus is the design of molecules with high selectivity against specific proteins in malignant cells, to insure a high therapeutic index with minimal side effects. The unprecedented success of the $\mathrm{BCR} / \mathrm{ABL}$ tyrosine kinase inhibitor imatinib (STI571/Gleevec, Novartis) in the treatment of chronic myeloid leukemia (CML) has inspired great expectations for this approach $(1,2)$. Complete hematologic responses to imatinib are seen in $>95 \%$ of CML patients and a major cytogenetic response in $>60 \%$ of patients treated in the chronic phase of the disease $(3,4)$. However, highly specific protein inhibition brings with it a critical problem: protein targets develop escape mutations leading to drug resistance. In fact, virtually all patients with advanced stages of CML ultimately manifest imatinib resistance (5-7), and it is expected that other protein targets will evolve drug resistant forms as well in response to therapy. The identification of these mutant forms is essential for the design of more robust next generation therapies, and may ultimately lead to molecular cocktails designed to circumvent resistance.

In previous work, we reported the results of a screen involving random mutagenesis of $\mathrm{BCR} / \mathrm{ABL}$ to reveal the spectrum of 
mutations conferring resistance to imatinib. The results not only identified the mutants critical for clinical disease relapse, but also shed light on the mechanism of auto-inhibition of the Abl kinase (8). Here we provide additional methodologic detail to enable a broader application of this screening strategy to additional drug-target pairs.

\section{MATERIALS AND METHODS}

\section{Overview}

To identify a wide spectrum of drug resistance conferring mutations, we generated a high complexity library of mutagenized BCR-ABL cDNA in a retroviral vector and introduced this into cells by retroviral transduction. We then selected for surviving drug-resistant clones, recovered plasmid DNA or PCR amplicons, and analyzed their sequence for the presence of mutations. To verify that the observed mutations were the basis of drug resistance, we regenerated each mutation separately by site-directed mutagenesis of native BCR-ABL, and reintroduced them into cells.

Briefly, the strategy is as follows (see Fig. 1):

- Clone the target cDNA into a retroviral vector.

- Propagate the vector in bacteria deficient in DNA repair mechanisms, creating an exhaustive library of mutations in the target gene.

- Transfect/infect drug-sensitive cells with the mutated vector and disperse in soft agar in the presence of drug.

- Isolate resistant colonies, recover the target cDNA, and sequence to identify mutations.

The resistant phenotype of the mutations is then confirmed as follows:

- Mutations are recreated in the native cDNA by site directed mutagenesis.

- Cells are transfected/infected and grown in the presence of drug.

- Resistance is measured by proliferation assays and/or immunoblotting.

- Mutations can be analyzed for their structural consequences by mapping onto a model of the protein crystal structure.

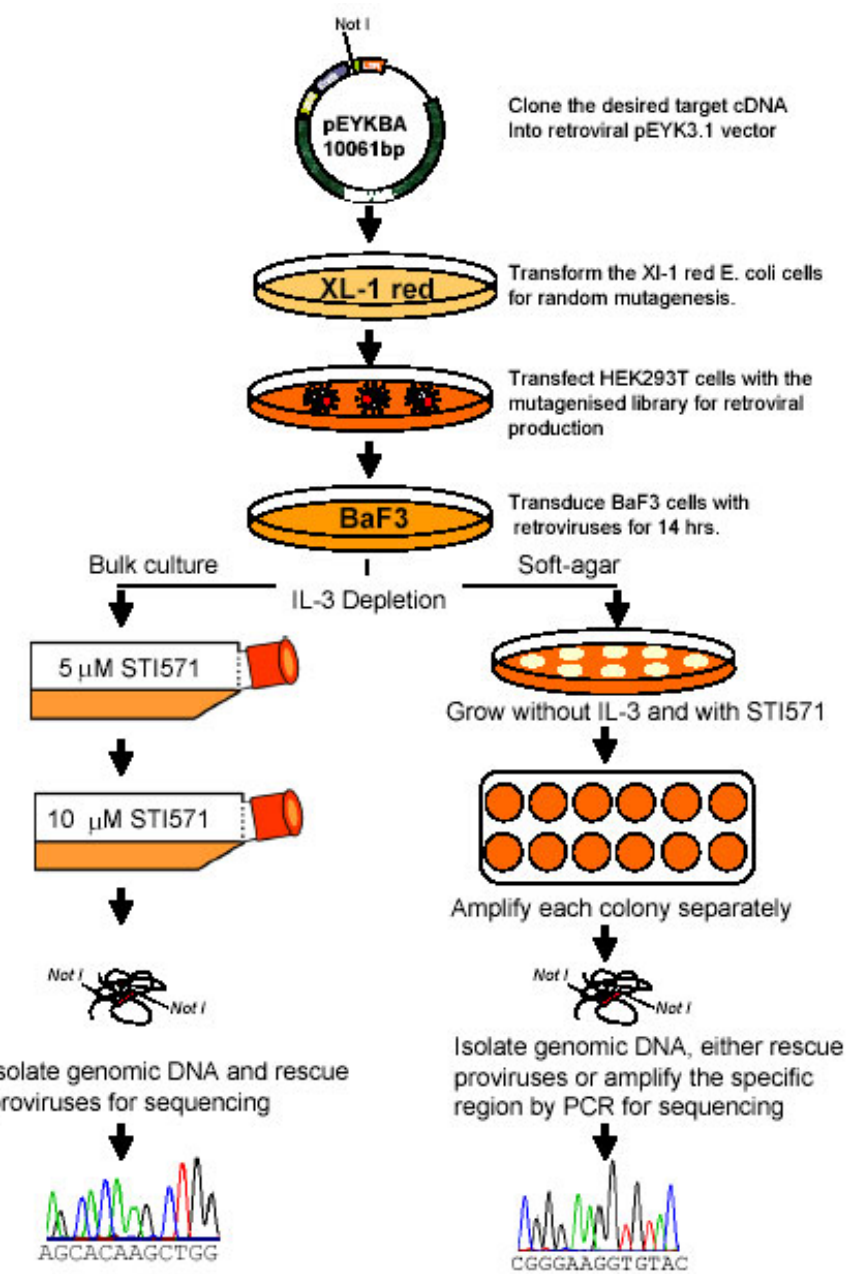

Fig. 1: General strategy for a drug resistance screen of a drug target pair.

\section{Retroviral construct, library generation and mutagenesis}

Full length BCR-ABL cDNA was cloned into the EcoRI site of the pEYK3.1 retroviral vector (8), generating pEYKBA. Using XL-1 Red competent E.coli cells (Stratagene) deficient in DNA repair mechanisms, $1 \mathrm{ug}$ of DNA was transformed according to the manufacturer's recommendations. More specifically, 10-50 ng of DNA (any more than $100 \mathrm{ng}$ decreases transformation efficiency) was mixed with $100 \mu$ l of competent cells in a prechilled polypropylene tube and incubated on ice for $30 \mathrm{~min}$, gently swirling every $2 \mathrm{~min}$. The tube was then immersed in a water bath at $42^{\circ} \mathrm{C}$ for a heat shock of 45 seconds and incubated on ice for $2 \mathrm{~min}$. Next, $1 \mathrm{ml}$ of SOC medium (2.0\% tryptone, $0.5 \%$ yeast extract, $0.05 \% \mathrm{NaCl}, 10 \mathrm{mM} \mathrm{MgCl}_{2}, 10 \mathrm{mM} \mathrm{MgSO}_{4}$, and $0.4 \%$ D-glucose) was added and the tube incubated at $37^{\circ} \mathrm{C}$ while shaking at $225-250 \mathrm{rpm}$ for $90 \mathrm{~min}$. The cells were then plated onto 4-8 LB-agar/zeocin plates $(25 \mathrm{ug} / \mathrm{ml}$ Zeocin from Invitrogen) and incubated at $37^{\circ} \mathrm{C}$. After $18-24 \mathrm{hrs}$, the colonies 
were collected by scraping the plates with a sterile plate scraper and plasmid DNA was isolated using the Qiagen Miniprep Kit. At this stage, the heterogeneity of mutations in each plasmid can be roughly assessed by restriction digest with a frequent cutter such as Sau3A1 or Taq1.

\section{Production of retroviral supernatants}

One day before transfection, 5 x $10^{5} \mathrm{HEK} 293 \mathrm{~T}$ cells were plated onto $60 \mathrm{~mm}$ dishes in DMEM containing 10\% FCS, pen/strep and $2 \mathrm{mM}$ L-glutamine. The medium was replaced the next day and cells transfected with either the mutagenized pEYKBA library or the native pEYKBA plasmid in the presence of FuGENE6 (Roche) and a 1:1 ratio of retroviral construct to retroviral packaging construct pCL-eco (8). The medium was changed and viral supernatant collected and filtered through a $0.45 \mu \mathrm{m}$ Acrodisc filter $16 \mathrm{hr}$ and $30 \mathrm{hr}$ respectively post transfection.

\section{Retroviral transduction}

The $\mathrm{BaF} 3$ cell line is a murine pro $\mathrm{B}$ cell line that is dependent on Interleukin-3 (IL-3) for growth. Ectopic expression of constitutive tyrosine kinases such as $\mathrm{BCR}-\mathrm{ABL}$ render the $\mathrm{BaF} 3$ cells IL-3 independent (10). BaF3 cells have a low intrinsic background of spontaneous transformation. $\mathrm{BaF} 3$ cells were grown in RPMI medium containing 10\% FCS, pen/strep, $2 \mathrm{mM}$ L-glutamine, and 5\% WEHI-3B conditioned medium (a source of IL-3). With a range of $10^{5}-10^{8}$ infectious units $/ \mathrm{ml}$ of retroviral supernatant, we infected $1 \times 10^{6} \mathrm{BaF} 3$ cells along with 8 $\mu \mathrm{g} / \mathrm{ml}$ polybrene (Sigma) and centrifuged for $90 \mathrm{~min}$ at 2500 $\mathrm{rpm}, 33^{\circ} \mathrm{C}$ in a Sorvall RT 6000 table centrifuge. Following an incubation of $14-16 \mathrm{hr}$ at $37^{\circ} \mathrm{C}, 5 \% \mathrm{CO}_{2}$, selection for Imatinib resistant cells was initiated by removal of IL-3 from the medium by washing the cells in WEHI-3B free RPMI/10\% FCS. We have employed low viral transduction efficiency (e.g. 20-30\%) in order to avoid inducing a drug resistant phenotype due to multiple proviral integrations.

\section{Screening for resistance}

To select for drug resistant BCR-ABL mutants, the infected cells were plated in soft agar containing varying concentrations of imatinib. More specifically, $8 \times 10^{6}$ cells were mixed with $28.8 \mathrm{ml}$ RPMI, $9.6 \mathrm{ml} \mathrm{FCS}, 9.6 \mathrm{ml}$ of $1.2 \%$ Bacto-agar (made in PBS, autoclaved and cooled to $42^{\circ} \mathrm{C}$ ), and supplemented with concentrations of $5-10 \mu \mathrm{M}$ imatinib. The mix was then plated, 3 $\mathrm{ml} /$ well, into 6 -well plates and incubated at $37^{\circ} \mathrm{C}, 5 \% \mathrm{CO}_{2}$, for 10 days before single colonies were picked and expanded separately in $3 \mathrm{ml}$ RPMI $/ 10 \%$ FCS in the presence of $5-10 \mu \mathrm{M}$ imatinib. Following expansion, genomic DNA was isolated using the Qiagen DNeasy Kit and sequenced. Two approaches for sequencing were compared. Both strategies are described below.

\section{Sequencing of PCR products}

Specific sub-regions of BCR-ABL cDNA were amplified by PCR using the following primers:

SH3-SH2 (f) 5'-CTCCACACTGTCCACAGCATTCC-3'; SH3-SH2 (r) 5'-CTGTCATCAACCTGCTCAGGC-3'; SH2-kinase (f) 5'-CGTGAGAGTGAGAGCAGTCC-3'; SH2-kinase (r) 5'-GCAGCTCTCCTGGAGGTCCTCG-3'.

The PCR products were then sequenced and analyzed by DNASTAR II.

\section{Provirus rescue from genomic DNA}

Provirus was extracted from genomic DNA as described previously (9). Briefly, $10 \mu \mathrm{g}$ of genomic DNA were digested with NotI to release the provirus. The provirus was then selfligated under dilute conditions $(100 \mu$ l of reaction volume per $1 \mu \mathrm{g}$ of genomic DNA), phenol/chloroformed extracted and ethanol precipitated. TOP10 competent cells (Invitrogen) were transformed with the ligation and plated onto LBagar/zeocin plates. Colonies were picked, expanded in liquid culture overnight, and the plasmid DNA isolated. The isolated clones were reintroduced into $\mathrm{BaF} 3$ cells and plated in the presence of imatinib to verify drug resistance. Finally, the drug resistant clones were sequenced to analyze their mutations.

\section{Site-directed mutagenesis}

Site-directed mutagenesis was performed on the native pEYKBA plasmid using the Quickchange Mutagenesis Kit from Strategene and oligonucleotides that were designed to create the point mutations found in our screen. Each mutant created was confirmed by sequencing.

\section{Cell viability assay to determine IC50}

$10^{4} \mathrm{BaF} 3$ cells expressing mutant pEYKBA were plated into each well of a 96-well plate in RPMI/10\% FCS. Imatinib was added to the media in increasing concentrations (final concentration: $0,1,3,5,10$, and $20 \mu \mathrm{M}$ ) across the plate and cells incubated for $60 \mathrm{hr}$. Cell viability was assessed with the WST-1 reagent (Roche) according to the manufacturer's recommendations and read with an ELISA plate reader at 450 nm. All assays were performed in quadruplicate and readings averaged and plotted against imatinib concentration as a best fit sigmoidal curve by using a nonlinear curve-fitting algorithm (Origin 7.0, Origin Lab, Northhampton, MA). The drug concentration resulting in $50 \%$ cell viability was scored as the Cellular IC50. 


\section{RESULTS AND DISCUSSION}

We have developed a general method to identify the spectrum of amino acid substitutions in a target oncoprotein that confer resistance to a target-directed small molecule anti-cancer agent. Our strategy was to first generate random point mutations in the target oncogene, and thereby create a complex library with single amino acid substitutions in every residue of the oncoprotein product. Next, we introduced this library into cells susceptible to transformation, and selected for the transformed phenotype in the presence of drug. We then isolated the resistant cells and sequenced the mutated target gene to reveal putative mutations. To validate the resistant phenotype of each candidate mutation, we recreated each mutation de-novo by site-directed mutagenesis, infected fresh cells, and confirmed their drug-resistant transformation.

We have used this strategy to define the spectrum of mutations in BCR-ABL that confer resistance to imatinib. We identified 112 such amino acid substitutions - a catalogue of mutations that is more comprehensive than discovered by clinical surveys to date. In addition to all major mutations detected in patients, we identified novel substitutions of residues both within and beyond the kinase domain (3). Some of the novel mutants discovered in our screen have since been found in patients (5-7), demonstrating the ability of the screen to anticipate clinically problematic drug resistance.

Random mutagenesis offers several advantages over the more popular PCR-based mutagenesis methods. Larger DNA fragments can be mutagenised in a relatively simple plasmid propagation procedure, while larger fragments are a challenge for PCR amplification. PCR mutagenesis also requires additional cumbersome and time-consuming steps to subclone the mutagenised DNA into an expression vector. We have screened 8 million cells with retroviral transduction efficiency of $20 \%$, which should give rise to 1.6 million independent clones of cells containing mutant Bcr-Abl. On the basis of this calculation each mutant plasmid is represented approximately 160 times in the screen.

During our screen, we found that it is important to avoid bulk culture conditions in which cells harboring different mutations are pooled together and allowed to expand in liquid culture, since this can lead to clonal dominance of a few highly drug-resistant variants. When we initially selected for imatinib-resistance of mutagenized BCR/ABL in bulk liquid culture, we found only 4 mutant forms that were represented multiple times within the first 100 isolates we sequenced. In contrast, we identified over 100 mutants when we selected for outgrowth of clones in the soft agar colony-forming assay. Some slow-growing clones with more modest degrees of drug resistance could not have been recovered using bulk culture. We thus recommend to avoid any growth or selection in bulk, either within the bacterial or mammalian cell cultures. For that reason, we attempted to minimize any incubation periods where cells are pooled together.
After retroviral infection, we maintained the cells in bulk culture prior to selection for only 14 to 16 hours, after which we performed combined IL-3 withdrawal and drug selection in soft agar. This provided for tight selection of individual clones and prevented clonal dominance of liquid cultures. If the cells used for drug screening do not form colonies in soft agar they can be selected in a similar clonal manner by limiting dilution in 96 well plates.

Once candidate mutations are isolated, it is imperative to confirm their ability to confer resistance in isolation, since some plasmids may house multiple mutations or false-positive amino acid substitutions that co-exist with other true resistant variants. It is also important to recognize that some classes of mutation, like allosteric variants occurring outside the catalytic site of a target enzyme, might generate subtle degrees of drug resistance that while not clinically meaningful can provide invaluable insights into enzyme regulation. For our BCR-ABL screen, we recreated a majority of the mutations using site directed mutagenesis of the native target kinase, and introduced the mutants into fresh cells. These cells were then grown in the presence of drug and assessed for their level of drug resistance. We tested cell viability in varying drug concentrations to determine individual mutant's IC50, and assessed BCR-ABL enzymatic activity by determining the degree of autophosphorylation by Western blot analysis. We validated the resistance profile for the vast majority of candidate mutations recovered in our primary screen, and found that less than $10 \%$ of the mutations were false positives (8).

Given the increasing trend toward development of target specific small molecule inhibitors for cancer therapy, it is essential to define the spectrum of clinically problematic resistanceconferring mutations to newly developed drugs. This will allow patient monitoring for early detection of drug resistance, and the design of more robust next-generation therapies. We have employed our screening strategy to identify mutations in the beta subunit of the farnesyl protein transferase that confer resistance to farnesyl transferase inhibitors, an unrelated class of anticancer compounds (Raz et al., unpublished). Thus we believe that the screening method will be generally applicable to a broad range of anti-cancer or anti-proliferative compounds, and should also be effective at defining drug resistant variants in viral, bacterial, and fungal targets using a similar combination of bacterial mutagenesis, cell selection, plasmid rescue, and sequencing.

\section{ACKNOWLEDGMENTS}

This work was supported by grants from the National Institutes of Health. GQD is the Birnbaum Scholar of the Leukemia and Lymphoma Society of America.

\section{REFERENCES}

1. Druker BJ, Tamura S, Buchdunger E, Ohno S, Segal GM, Fanning S, Zimmermann J, Lydon NB. Effects of a selective 
inhibitor of the Abl tyrosine kinase on the growth of BcrAbl positive cells. Nat Med 1996; 2(5):561-566.

2. Druker BJ, Sawyers CL, Kantarjian H, Resta DJ, Reese SF, Ford JM, Capdeville R, Talpaz M. Activity of a specific inhibitor of the BCR-ABL tyrosine kinase in the blast crisis of chronic myeloid leukemia and acute lymphoblastic leukemia with the Philadelphia chromosome. N Engl J Med 2001; 344:1038-1042.

3. Dancey J, Sausville EA. Issues and progress with protein kinase inhibitors for cancer treatment. Nat Rev Drug Discov 2003; 2:296-313.

4. O'Brien SG, Guilhot F, Larson RA, Gathmann I, Baccarani M, Cervantes F, Cornelissen JJ, Fischer T, Hochhaus A, Hughes T, Lechner K, Nielsen JL, Rousselot P, Reiffers J, Saglio G, Shepherd J, Simonsson B, Gratwohl A, Goldman JM, Kantarjian H, Taylor K, Verhoef G, Bolton AE, Capdeville R, Druker BJ; IRIS Investigators. Imatinib compared with interferon and low-dose cytarabine for newly diagnosed chronic-phase chronic myeloid leukemia. N Engl J Med 2003; 348:994-1004.

5. Gorre ME, Mohammed M, Ellwood K, Hsu N, Paquette R, Rao PN, Sawyers CL. Clinical resistance to STI-571 cancer therapy caused by BCR-ABL gene mutation or amplification. Science 2001; 293:876-880.

6. Shah NP, Nicoll JM, Nagar B, Gorre ME, Paquette RL, Kuriyan J, Sawyers CL. Multiple BCR-ABL kinase domain mutations confer polyclonal resistance to the tyrosine kinase inhibitor imatinib (STI571) in chronic phase and blast crisis chronic myeloid leukemia. Cancer Cell 2002; 2:117-125.

7. Branford S, Rudzki Z, Walsh S, Grigg A, Arthur C, Taylor K, Herrmann R, Lynch KP, Hughes TP. High frequency of point mutations clustered within the adenosine triphosphatebinding region of $\mathrm{BCR} / \mathrm{ABL}$ in patients with chronic myeloid leukemia or Ph-positive acute lymphoblastic leukemia who develop imatinib (STI571) resistance. Blood 2002; 99(9):3472-3475.

8. Azam M, Latek LR, Daley GQ. Mechanisms of Autoinhibition and STI-571/Imatinib Resistance Revealed by Mutagenesis of BCR-ABL. Cell 2003; 112:831-843.

9. Koh EY, Chen T, Daley GQ. Enhanced cDNA Rescue Strategies to Facilitate Functional Genomic/Phenotypic Screens in Mammalian Cells. Nucleic Acids Res 2002; 30:E1422.

10. Daley GQ, Baltimore D. Transformation of an interleukin 3dependent hematopoietic cell line by the chronic myelogenous leukemia-specific $\mathrm{P} 210 \mathrm{bcr} / \mathrm{abl}$ protein. Proc Natl Acad Sci USA 1988; 85:9312-9316. 


\section{PROTOCOLS}

\section{Mutagenesis and library construction}

\section{$X L-1$ Red transformation}

Thaw $100 \mu \mathrm{l}$ XL-1 Red competent E-Coli (Stratagene), in a polypropylene tube on ice.

Gently mix in 10-50ng plasmid DNA.

Incubate on ice for $30 \mathrm{~min}$, gently swirling every two minutes.

Immerse the tube in a $42^{\circ} \mathrm{C}$ bath for $45 \mathrm{sec}$ and immediately incubate on ice for $2 \mathrm{~min}$.

Add $1 \mathrm{ml}$ SOC medium and incubate at $37^{\circ} \mathrm{C}$ shaking at $225-250 \mathrm{rpm}$ for $90 \mathrm{~min}$.

Plate the cells on 4 to 8 Zeocin plates $\left(25 \mu \mathrm{g}\right.$ Zeocin per $\mathrm{ml}$ of LB-Agar) and incubate at $37^{\circ} \mathrm{C}$ for $18-24$ hours.

Collect the bacterial colonies by scraping the plates with sterile plate scrapers (pooling together all colonies on the plate).

Isolate DNA by maxiprep using Qiagen kit according to manufacturer's instructions (miniprep can also be used).

SOC medium

$2 \%$ tryptone

$0.5 \%$ yeast extract

$0.05 \% \mathrm{NaCl}$

$10 \mathrm{mM} \mathrm{MgCl}_{2}$

$10 \mathrm{mM} \mathrm{MgSO}_{4}$

0.4\% D-glucose

\section{Production of retroviral supernatants}

Day 0 - Plate $5 \times 10^{5} \mathrm{HEK} 293 \mathrm{~T}$ cells in DMEM (10\% FCS, $50 \mathrm{u} / \mathrm{ml}$ penicillin, $50 \mu \mathrm{g} / \mathrm{ml}$ streptomycin, $2 \mathrm{mM}$ glutamine) in a $60 \mathrm{~mm}$ plate. Incubate at $37^{\circ} \mathrm{C}, 5 \% \mathrm{CO}_{2}$ overnight.

Day 1 - Mix together in order: DME up to $100 \mu$, mutagenized retroviral plasmid DNA (1 $\mu$ g), PCL/Eco retroviral packaging construct $(1 \mu \mathrm{g}$ ), and $6 \mu \mathrm{l}$ Fugene6 (Roche) and incubate at room temperature for $15 \mathrm{~min}$.

Replace the medium of the HEK 293T cells carefully (to prevent them from lifting off the plate).

Pipette the $100 \mu \mathrm{l}$ of the Fugene 6 mixture onto the plate and incubate at $37^{\circ} \mathrm{C}, 5 \% \mathrm{CO}_{2}$.

Day 2 - Replace the medium 16-24 hours after transfection and incubate for an additional 15-24 hours.

Day 3 - Collect and filter the supernatant through a $0.45 \mu \mathrm{m}$ filter (Acrodisc).

Use immediately for infection (or freeze at $-80^{\circ} \mathrm{C}$ ).

\section{Retroviral Infection}

Retroviral supernatant should be titered to optimize infection efficiency. In general:

1. Plate $2.5 \times 10^{5}$ of the target cells (BaF3 in our case) in each well of a 6 well plate using fresh medium (if adherent cells are used they should be allowed to adhere overnight before infection).

2. Calculate the desired concentration of the filtered supernatant and add to each well (usually between $400-1000 \mu \mathrm{l}$ ).

3. Centrifuge at $2500 \mathrm{rpm}$ for $90 \mathrm{~min}$ at $33^{\circ} \mathrm{C}$ in a Sorvall RT6000 table centrifuge.

4. Apply appropriate selection 16 hours after infection. For BaF3 cells remove medium, wash with PBS and add RPMI (with out WeHi-3b). Incubate at $37^{\circ} \mathrm{C}, 5 \% \mathrm{CO}_{2}$ for an additional 14 hours. - This step is not necessary. Alternatively skip directly to drug resistance selection (16 hours after infection).

\section{Drug resistance selection}

1. Mix together $8 \times 10^{6}$ infected cells in $28.8 \mathrm{ml}$ RPMI with $9.6 \mathrm{ml} \mathrm{FCS}$, and the appropriate drug concentration.

2. Add $9.6 \mathrm{ml}$ of $1.2 \%$ Bacto-agar (made in PBS, autoclaved, and cooled to $42^{\circ} \mathrm{C}$ ).

3. Immediately plate $3 \mathrm{ml}$ in each well of a 6 well plate, filling 16 wells all together.

4. Incubate the cells for $10-14$ days at $37^{\circ} \mathrm{C}, 5 \% \mathrm{CO}_{2}$.

5. Pluck single colonies and expand in $3 \mathrm{ml}$ RPMI $(10 \% \mathrm{FCS})$ in the presence of drug.

6. Once the cells are confluent use the DNeasy Kit (Qiagen) to isolate genomic DNA according to manufacturer's instructions. 
7. Amplify the mutagenized DNA using appropriate primers and sequence.

\section{Resistance testing}

\section{IC50 cell viability assay}

1. Plate $0.5-1 \times 10^{4}$ cells expressing the mutant construct in each well of a 96 well plate using $50 \mu$ l of the appropriate medium.

2. Add $50 \mu \mathrm{l}$ cell medium with a $2 \mathrm{X}$ drug concentration to each well. Use a range of concentrations that will span from weak to strong target inhibition (for example $0,1,3,5,10$, and $20 \mu \mathrm{M}$ in the case of Imatinib). Keep one well with no cells to use as reference for the ELISA readout.

3. Allow the cells to incubate in drug for 36-60 hours.

4. Add the WST-1 reagent (Roche) to each well according to manufacturer's instructions.

5. Read using an ELISA reader at 450nm. 